\title{
İşyeri Arkadaşı̆ı̆ı, Mesleki Tatmin, İş Stresi İlişkisi: Bir Alan Araştırması ${ }^{1}$
}

\author{
İsmail BAKAN
}

Prof. Dr., Kahramanmaraş Sütçü İmam Üniversitesi, İktisadi ve İdari Bilimler Fakültesi, İşletme Bölümü, ibakan63@hotmail.com

Orcid ID: http://orcid.org/0000-0001-8644-8778

\section{Mustafa Tuncer OKUMUŞ}

Doktora Öğrencisi, Kahramanmaraş Sütçü İmam Üniversitesi, Sosyal Bilimler Enstitüsü, İşletme Ana Bilim Dalı mtokumus@hotmail.com

Orcid ID: http://orcid.org/0000-0002-6495-3252

\section{Merve Rabia KUTLUK}

Yüksek Lisans Öğrencisi, Kahramanmaraş Sütçü İmam Üniversitesi, Sosyal Bilimler Enstitüsü, İşletme Ana Bilim Dalı kutlukmerve@gmail.com

Orcid ID: http://orcid.org/0000-0003-0926-5892

\section{Öz}

İşyeri arkadaşlıkları, çalışanların bugünün modern iş dünyasında mesleklerini yerine getirmelerinde ihtiyaç duydukları önemli bir kavram olarak görülmektedir. İşyerlerinde geniş arkadaş ağına sahip çalışanlar tarafindan algılanan tatmin düzeyinin daha yüksek olduğuna inanılmaktadır. Mesleki tatmin düzeyi ile çalışanın yaşadığ iş stresi arasında da bir ilişki olduğu kabul edilir. Bu çalışmada, Malatya'da faaliyet gösteren özel eğitim kurumlarının çalışanları üzerinde yapılan bir alan araştırması ile işyeri arkadaşlı̆̆ının mesleki tatmin üzerindeki ve mesleki tatminin iş stresi üzerindeki etkisi araştırılmıştır. Araştırma verileri, anket tekniği kullanılarak 192 kişiden elde edilmiştir. Veriler SPSS programı ile analiz edilmiştir. Analiz kapsamında frekans, güvenilirlik, korelasyon ve regresyon analizi yapılmıştır. Analiz sonuçlarına göre; Özel eğitim kurumlarında çalışanların işyerinde arkadaşlık düzeylerinin mesleki tatmin düzeyini artırdığ 1

\footnotetext{
${ }^{1}$ Makale Geliş/Kabul Tarihi: 22.04.2020 / 28.04.2020

Künye Bilgisi: Bakan, I.; Okumuş, M.T. ve Kutluk, M.R. (2020). İşyeri Arkadaşlı̆̆l, Mesleki Tatmin, İ̧̧ Stresi Iliş̧kisi: Bir Alan Araştırması. Kahramanmaraş Sütçü İmam Üniversitesi Sosyal Bilimler Dergisi, 17 (1), 258-273. DOI: 10.33437/ksusbd.725311
} 
ve mesleki tatminin artması durumunda iş stresinin azaldığ sonucuna ulaşı1mıştır.

Anahtar Kelimeler: İşyeri Arkadaşlığı, Mesleki Tatmin, İş Stresi.

\title{
The Relationship between Workplace Friendship, Compassion Satisfaction and Job Stress: A Field Study
}

\begin{abstract}
Workplace friendships are seen as an important concept that employees need in fulfilling their professions in today's modern business world. It is believed that the level of satisfaction perceived by friends and employees with wide network of friends in their workplaces has increased. It is anticipated that it decreases the work stress experienced by the employee in the increase in the level of professional satisfaction. In this study, the effect of workplace friendship on professional satisfaction and the effect of professional satisfaction on job stress were investigated with the employees of private education institutions operating in Malatya. The research data were obtained from 192 people working in private educational institutions operating in Malatya using the survey technique. The data were analyzed with SPSS program. Within the scope of the analysis, frequency, reliability, correlation and regression analysis were performed. According to the results of the analysis; it has been concluded that workplace friendship levels of employees of private educational institutions increase the level of professional satisfaction and in case of increased professional satisfaction, work stress decreases.
\end{abstract}

Keywords: Workplace Friendship, Compassion Satisfaction, Job Stress.

\section{GíRIŞ}

Çalışanlar görevlerini yerine getirirken işyerinde bulunan diğer işgörenlerle gerek iş yaparken gerekse boş zamanlarında iletişim kurarak paylaşımlarda bulunmaktadırlar. $\mathrm{Bu}$ durum çalışanlar arasında işyeri arkadaşlığı olarak adlandırılmaktadır. İşyeri arkadaşlıklarında romantik ilişkilerden farklı olarak duygusal bağlılık vardır. İşyeri arkadaşlıkları gelişerek büyümekte olup gelişimlerinin doğası diğer ilişkilerden farklıdır. Arkadaşlıklar isteğe bağlıdır ve kişisel odaklıdır (Sias ve Cahill, 1998:275). Çalışanların işyeri arkadaşlıkları örgütleri ile uyumu artırıcı ve hızlandırıcı etki oluşturabilmektedir (Alparslan vd., 
2015:188). Çalışanların işyeri arkadaşlıklarında demografik değişkenlerden daha çok, birlikte çalışılan birim etkili olmaktadır (Şahinbaş ve Erigüç, 2019:1219). İşyeri arkadaşlıkları sayesinde çalışanların karşılaştıkları güçlüklerle baş edebilmeleri daha kolay hale gelebilmekte ya da tam tersi durumda daha da güçleşmektedir. Genel olarak hizmet sektöründe ve özel gereksinimli veya özel eğitime ihtiyacı bulunan bireylere yönelik hizmet veren kurumlarda görev yapan çalışanlar, çalışma şartlarına bağlı olarak birçok güçlükle karşı karşıya kalabilmektedir. Bu kurumlarda çalışanlar hem özel bir alanda hizmet üretirken yaşadıkları fiziki ve psikolojik güçlükler, hem de iş ortamlarından kaynaklanan bir takım örgütsel zorluklarla baş etmek durumunda kalabilmektedirler. Hizmet verdikleri kişilerin fiziksel ya da zihinsel gereksinimlerinden kaynaklanan yardım davranışları sırasında çalışanlar hem mesleklerini icra etmekte hem de işlerinin gereği olarak yardımcı oldukları bireylere mesleki ilgi, hizmet ve şefkat davranışı göstermeleri gerekmektedir. Bunun sonucunda da işgörenlerde mesleklerini yaparken yaşadıkları olumlu mesleki duygular ortaya çıkmaktadır.

Mesleki tatmin profesyonel yaşam kalitesini pozitif olarak etkileyen bir öncül durumundadır. Birisinin işini yapmanın hem olumlu hem de olumsuz yönleri, profesyonel yaşam kalitesini etkilemektedir. Profesyonel yaşam kalitesi, kişinin yardım eden kişi olarak yaptığı çalışmalarla ilgili hissettiği kalitedir. Hizmet eden çalışanlar; sağlık uzmanları, sosyal hizmet çalışanları, öğretmenler, avukatlar, polis memurları, itfaiyeciler, din adamları, havayolu ve diğer ulaşım personeli, afet bölgesi temizlik ekiplerinde çalışanlar ve etkinlik sırasında veya sonrasında yardım sunan diğer kişiler olabilirler (Stamm, 2010:8). Hizmet alan bireyler bir süre sonra değişse dahi uzun süreler boyunca karşı karşıya kaldıkları durumlar çalışanların profesyonel yaşam kalitesini ve mesleki tatmin düzeylerini etkileyebilmektedir.

İşyeri birçok stres kaynağının bulunduğu bir ortamdır. İşyerlerinde yaşanan stres, hem toplumsal hem de işin kendisinden kaynaklanan boyutlara sahiptir. Bir işyerinde bulunan çalışanların bir bölümü benzer koşullardan daha az etkilenirken bir bölümü de daha fazla olumsuz etkilenebilmektedir (Aktaş, 2001:26).

İşgörenlerin sahip oldukları arkadaşlık düzeylerinin mesleklerini uygularken algıladıkları mesleki tatmin düzeyini de etkileyeceği öngörülmektedir ve bu araştırmanın konusunu oluşturmaktadır. Çalışanların mesleklerini yerine getirirken karşı karşıya kaldıkları durumların ve kurum içerisinde çalışma şartlarından kaynaklanan güçlüklerin işgörende strese sebep olabildiği bilinmektedir. Mesleki tatmin düzeyinin iş stresi üzerinde etkisi olup olmadığ 1 ve eğer varsa yönü ve etki düzeyi ise bu çalışmada ele alınan diğer bir konudur. Dolayısıyla, yapılan bu araştırmada, özel eğitim kurumlarında görev yapan 
çalışanlarda işyeri arkadaşlığının mesleki tatmin ve mesleki tatminin de iş stresi üzerindeki etkisi incelenmektedir.

\section{İŞYERİ ARKADAŞLIĞI}

İnsanlar arkadaşa ihtiyaç duyarlar. Arkadaşlık insanların manevi sağlığına dayanak noktası oluşturur. Arkadaşlar birbirlerine sevgi ve ilgi gösterirler. İnsanlar dostluğun güvenli alanında kendisini tanımaya başlar ve kendi isteklerini takip etmek için güven ve destek kazanırlar (Dobel, 2001:145). İşyeri arkadaşlığı, romantizmi dışlayan yollarla sadece tanıdıklığın ötesine geçen, işyerindeki insanlar arasında karşılıklı bağlılık, güven ve paylaşılan değerler ya da çıkarlar gerektiren bir kavramdır. İ̧̧yeri arkadaşlıkları bazen belirli iş alanlarıyla veya işle ilgili boş zamanlarla sınırlı olabilir (Berman vd., 2002:217). İşyerinde arkadaşlı̆̆ anlamak örgüt düzeyinde önemli bir bakış açısı oluşturmaktadır (Mao, 2006:1819). İşyeri arkadaşlığı; sosyal destek algısı oluştururken kendilerine, çalışma arkadaşlarına ve çalıştıkları örgüte güven duygusunun gelişmesini sağlamaktadır. İş görenlerin işyerindeki yakın arkadaşlıkları mutluluk ve motivasyon kaynağı olarak gördükleri, araştırmacılarca ifade edilmektedir (Alparslan vd., 2015:176).

İş yeri arkadaşlıklarının başlatılması, geliştirilmesi ve sürdürülmesi için iletişim çok önemlidir, çünkü iletişim ilişkinin kendisini oluşturur. İşyeri arkadaşlığının gelişimi için kişilik, ortak görevler, bilgi iletişim teknolojileri ve yüz yüze iletişim gibi iletişim kanallarını kullanma sıklığı işyeri arkadaşlığını olumlu olarak etkilemektedir (Sias vd., 2012:258). Bandura'nın sosyal öğrenme teorisine göre, yüksek işyeri arkadaşlık ortamlarını genellikle başkalarını destekleme ve bilgi paylaşımı oluşturmaktadır (Chang vd., 2016:260). Arkadaşlık ağları formel organizasyon vasıtasıyla ortaya çıkar ve çalışanların formel organizasyonla olan günlük birlikteliğinin bir parçasıdır (Riordan ve Griffeth, 1995:143; Morrison, 2009:1). İşyeri arkadaşlık ağı büyüklüğünün duygusal destek, güven, minnet duygusu ve görev performansı üzerinde önemli etkileri vardır. Çalışanlar daha fazla işyeri arkadaşına sahip oldukları zaman daha fazla duygusal destek ve güven yaşarlar (Methot, 2016:325). Arkadaşlık ilişkileri; kişilik problemleri, rahatsız edici yaşam olayları, çatışmalar, beklentiler, ihanet ve terfi etme sebepleri ile bozulabilmektedir. İşyeri arkadaşlı̆ııın bozulması duygusal stres ve performansta azalma gibi sonuçlar oluşturabilmektedir (Sias vd., 2004).

\section{MESLEKİ TATMIN}

Compassion satisfaction kavramı için Türkiye' de yapılmış olan çalışmalarda eşduyum memnuniyeti, merhamet memnuniyeti ve mesleki tatmin ifadelerinin kullanıldığ1 görülmektedir (Yeşil vd., 2010; Hiçdurmaz ve İnci, 2015; Bozgeyikli, 2016; Yılmaz ve Üstün, 2018). Kavramın Türkçe karşıllı̆̆ ile ilgili 
olarak literatürde ortak bir dil oluşmadığı anlaşılmaktadır. Yapılan bu çalışmada mesleki tatmin ifadesi tercih edilmiştir.

Stamm (2010) tarafindan geliştirilen bir terim olan mesleki tatmin, (compassion satisfaction) çalışanın kendi mesleği veya işiyle ilgili bir alanda yardıma ihtiyacı olan bir başka kişiye yardım etmesi sonucunda duyduğu tatmin ve memnuniyet duygusu (Conrad ve Kellar-Guenther, 2006:1073-1074; Karakaş, 2016:2744), birisine yardım eden kişinin işlerini iyi yapmaktan aldığ 1 haz ve başkalarının iyiliğine katkıda bulunma kabiliyeti olarak tanımlanmaktadır (Harr, 2013:74). Mesleki tatmin aynı zamanda akut hasta veya travmatize olmuş kişilerle çalışmanın olumsuz yönlerini "dengelemeye" yardımcı olan yardımseverliğin olumlu bir yönüdür (Hooper vd., 2010:422). Bireyin hizmet ettiği kişilere uzun süreli şefkat göstermesi kişide bir mesleki tatmin duygusu oluşturabilmektedir (Alkema vd., 2008:104). İşini etkili bir şekilde yapabilmekten kaynaklanan haz alma (Stamm, 2005, akt., Craig ve Sprang, 2010:322) ve yardım etme kabiliyetine dair olumlu duygular olan mesleki tatmin iş yaşam kalitesi ile ilgili bir kavramdır (Wagaman vd., 2015:203).

İşyeri arkadaşlığının arkadaşlık firsatı ve sıkı arkadaşlık olmak üzere iki boyutu bulunmaktadır. İşyeri arkadaşlı̆ı açısından güçlü olan bireyin mesleki tatmin düzeyinin de yüksek olacağı varsayımından hareketle araştırmanın birinci ve ikinci hipotezi şu şekilde oluşturulmuştur.

H1. İsyeri arkadaşlı̆̆ııın arkadaşlık firsatı boyutu mesleki tatmini olumlu olarak etkiler. etkiler.

H2. İşyeri arkadaşlı̆̆ının sıkı arkadaşlık boyutu mesleki tatmini olumlu olarak

\section{İS STRESİ}

Stres, bir kişinin tehdit edici olarak algıladığı çeşitli durumlara bir tepkisi olup insanların stresörlere (çevrelerindeki baskı, talepler ve değişiklikler) verdiği olumsuz duygusal ve fiziksel reaksiyonların birleşimidir. Verilen tepki kişisel sağlı̆̆ın ve örgütsel etkinliğin bozulmasına sebep olabilmektedir. Kontrol edilemeyen stres, üretkenlik ve yenilikçiliği etkileyeceğinden stresini yönetemeyen çalışanlar kuruluş için bir maliyet oluşturmaktadır. Kurumlar tarafından ise stresin çalışanın yaşam tarzı, psikolojik yapısı ve kişiliği nedeniyle bireysel bir problem olarak görülme eğilimi vardır. Çalışanlar ise stresli çalışma ortamlarında aşırı talepler, zayıf yönetim veya çelişkili talepler sonuçlarıyla karşılaşabilmektedirler. Stres, modern işyerinde ciddi bir sorun oluşturmaktadır. İş stresi; iş güvenliği, zaman sınırlaması, iş yoğunluğu, yönetici ve/veya iş arkadaşı olumsuzluğu ve işyeri güvenliği gibi nedenlerle ortaya çıkabilmektedir (Speegle, 2013:283). 
Stresörler; işin özellikleri ve şartları; kuruluşun yapısı, iklimi ve bilgi akışı ile ilgili şartlar; rolle ilgili faktörler; işyeri ilişkileri; algılanan kariyer gelişimi ve dış taahhütler ile sorumluluklar olmak üzere altı kategoride ifade edilebilir (Parker ve DeCotiis, 1983:165). İşs stresi, işten ayrılma niyeti ve devamsılılk gibi sonuçlar ortaya çıkarabilmektedir (Gupta ve Beehr, 1979). Literatürde stres ve mesleki tatminle ilgili araştırmaların olduğu görülmektedir. Severn vd. (2012) yaptıkları çalışmada mesleki stres ile mesleki tatmin arasında anlamlı bir ilişki bulamadıklarını belirtmişlerdir. Li vd., (2014) ve Meyer vd. (2015) ise yaptıkları çalışmada, yüksek düzeyde strese maruz kalanların mesleki tatminlerinin düştüğü sonucuna ulaşmışlardır. Yapılan bu çalışmada ise mesleki tatmin ile iş stresi arasında ilişki olup olmadığı, şayet ilişki bulunmakta ise mesleki tatminin iş stresini ne düzeyde etkilediği sorusuna cevap aranmıştır. Bu sorunun cevabını bulmak için araştırmanın üçünü hipotezi şu şekilde oluşturulmuştur:

\section{H3. Mesleki tatmin, işstresini olumsuz etkiler.}

\section{ARAŞTIRMA YÖNTEMI}

Araştırmada, nicel araştırma yöntemi uygulanmıştır. Çalışmanın veri toplama sürecinde anket tekniğinden yararlanılmıştır. Veri toplamadan önce Kahramanmaraş Sütçü İmam Üniversitesi Sosyal ve Beşerî Bilimler Etik Kurulundan 02.04.2019 tarih 2020/9 toplant1 sayı ve 2 nolu kararı ile etik kurul kararı alınmıştır.

İşyeri arkadaşlığı değişkeni Nielsen vd. (2000) tarafından kullanılan iki boyutlu ölçek ile ölçümlenmiştir. Boyutlardan birisi "arkadaşlık firsatı" boyutu olup "İş arkadaşlarımı tanımak için firsatım var" ve "İş yerimde yakın dostluklar geliştirme firsatım var" şeklindeki 6 önerme ile ölçümlenmektedir. Diğer boyut ise "s1k1 arkadaşlık" boyutu olup "İş yerinde güçlü arkadaşl1klar kurdum" ve "İş yerinde insanlara güvenebilirim (sır verebilirim)" şeklindeki 6 önermeden oluşmaktadır.

Mesleki tatmin değişkeni, iş yaşam kalitesi ölçeğinin (Professional Quality Of Life Scale) bir boyutu olup, Stamm (2010) tarafindan geliştirilmiş ve Yeşil vd. (2010) tarafindan Türkçeye uyarlama çalışması yapılmış olan ölçek kullanılarak ölçümlenmiştir. Mesleki tatmin, "İşimi seviyorum" ve "İnsanlara yardım edebiliyor olmaktan memnun oluyorum" şekilde sorulardan oluşan 10 önerme ile ölçümlenmiştir. Mesleki tatmin ölçeği ile çalışanın kendi mesleği veya işiyle ilgili bir alanda yardıma ihtiyacı olan bir başka kişiye yardım etmesi sonucunda duyduğu tatmin ve memnuniyet duygusu ölçülmektedir (Bozgeyikli, 2016:98). Güvenilirlik düzeyi, Yeşil vd. (2010)'nin yapmış olduğu çalışmada 0.819 ve Bozgeyikli (2016)'nin özel öğretim kurum öğretmenlerine yönelik yaptı̆̆ çalışmada 0.850 olarak bulunmuştur. Benzer şekilde bu çalışmada da 0.889 olarak bulunmuştur. 
İş stresi ölçeği, Crank vd. (1995) tarafından geliştirilen ve Lambert vd. (2006)'nin çalışmalarında kullandıkları "İşteyken genellikle çok fazla baskı altındayım" ve "İşteyken sık sık gergin veya sinirli hissediyorum" şeklinde sorulardan oluşan 5 önerme ile ölçümlenmiştir. Ankette her bir ifade için "1.Kesinlikle Katılmiyorum", "2.Katılmıyorum", "3.Kararsızım", "4.Katılıyorum" ve "5.Kesinlikle Katılıyorum" dan oluşan 5 aşamalı Likert ölçeği ile değerlendirme yapılmıştır.

Toplanan veriler SPSS 21 istatistik paket programı kullanılarak değerlendirilmiştir. Öncelikle anketler güvenilirlik testine tabi tutulmuş, Cronbach's alfa güvenilirlik katsayısı bulunmuştur. Daha sonra kişisel tanımlayıcı istatistikler ortaya konulmuştur. Korelasyon testi ile önermeler arasındaki ilişki düzeyi ve yönü belirlenmiş, regresyon analizi ile hipotezler test edilmiştir. Analiz sonuçları tablolar halinde sunulup raporlanmış ve ortaya çıkan bulgular yorumlanarak çalışmanın sonucu ortaya konulmuştur.

\section{Araştırma Modeli}

Çalışmada işyeri arkadaşlığı ile mesleki tatmin ve mesleki tatmin ile iş stresi arasındaki ilişki ve etki düzeyi araştırılmıştır. Araştırma hipotezleri şu şekilde oluşmuştur:

H1. İşyeri arkadaşlığının arkadaşlık firsatı boyutu mesleki tatmini olumlu olarak etkiler.

H2. İsyeri arkadaşslı̆̆ının sıkı arkadaşlık boyutu mesleki tatmini olumlu olarak etkiler.

H3. Mesleki tatmin, işs stresini olumsuz etkiler.

Ortaya konulan hipotezlere göre araştırma modeli Şekil 1'de görüldüğü şekliyle oluşturulmuştur.

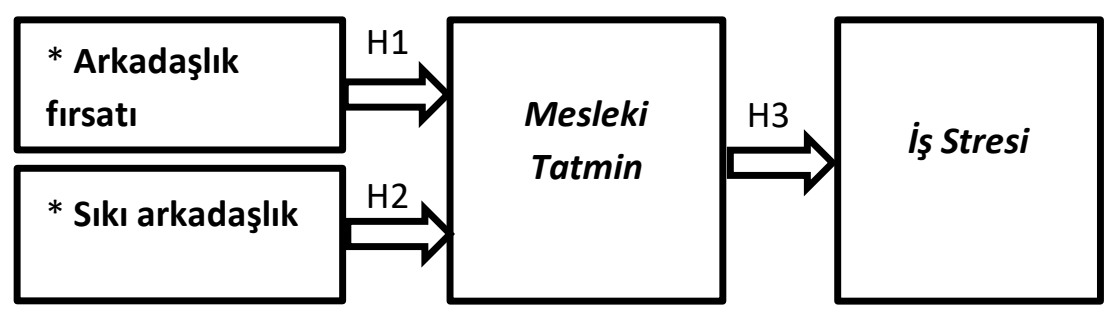

Şekil 1. Araştırma Modeli 


\section{Araştırmanın Evreni ve Örneklem}

$\mathrm{Bu}$ araştırmanın evrenini Malatya'da faaliyet gösteren özel eğitim kurumlarında görev yapan çalışanlar oluşturmaktadır. Araştırmada örneklem sayısının belirlenmesinde basit tesadüfî örneklem yönteminden yararlanılmıştır. Bu kapsamda, 200 özel eğitim kurum çalışanı örneklem olarak seçilip anket uygulanmış ve 192 kişiden elde edilen analizlerde kullanılabilir nitelikteki anketlerle çalışma tamamlanmıştır.

\section{Araştırmanın Güvenilirliği}

Ölçeklerin güvenirliğinin test edilmesinde Cronbach's Alfa kullanılmıştır. Literatüre göre alfa değeri 0,70 veya üzerinde bir değere sahip $(0,70 \leq \alpha \leq 1)$ ise ölçek güvenilir kabul edilmektedir. 0,80 ile 1 aralığında çıkan alfa katsayıları yüksek derecede güvenilir kabul edilmektedir (Gürbüz ve Şahin, 2016). Araştırma değişkenleri ile ilgili soru sayıları ve ölçeklerin güvenilirliğine ilişkin Cronbach's alfa değerleri Tablo 1'de yer almaktadır.

Tablo 1. Güvenilirlik Tablosu

\begin{tabular}{lcc}
\hline \multicolumn{1}{c}{ Değişkenler } & Önerme Sayısı & $\begin{array}{c}\text { Cronbach’s } \\
\text { Alfa }\end{array}$ \\
\hline $\begin{array}{l}\text { İşyeri Arkadaşlı̆̆ı- arkadaşık } \\
\text { firsatı }\end{array}$ & 6 & 0,853 \\
\hline İşyeri Arkadaşlığı- sıkı arkadaşık & 6 & 0,868 \\
\hline Mesleki tatmin & 10 & 0,889 \\
\hline İş stresi & 5 & 0,873 \\
\hline
\end{tabular}

Yapılmış olan çalışmada Cronbach's alfa güvenilirlik değerlerine bakıldığında; işyeri arkadaşlığı-arkadaşlık firsatı 0,853 , işyeri arkadaşlığı-sıkı arkadaşlık 0,868 , mesleki tatmin 0,889 ve iş stresi 0,873 olduğu görülmektedir. $\mathrm{Bu}$ bağlamda, tüm değişkenlerin yüksek derecede güvenilir bir şekilde ölçümlendiği bulgusuna ulaşılmıştır.

\section{DEMOGRAFIK DEĞISŞKENLER ILE ILGILİ TANIMLAYICI İSTATISTÍKLER}

Çalışanların demografik özellikleri ile ilgili araştırma sonuçları incelendiğinde, katılımcıların \%28,1'inin erkek, \%71,9'unun kadın olduğu görülmektedir. Medeni durum açısından bakıldığında, \%72,1'inin bekar ve 
\%27,9'unun evli olduğu anlaşılmaktadır. Katılımcıların \%71,4'ünün 20-30 yaş aras1, \%17,2'sinin 31-40 yaş aras1, \%4,2'sinin 41-50 yaş aras1, \%7,3'ünün 51 yaş ve üstünde yer aldıkları anlaşılmaktadır. Katılımcıların öğrenim durumu incelendiğinde; \%2,6's1 ön lisans, \%88,9'u lisans, \%6,3'ü yüksek lisans ve $\% 2,1$ 'i doktora seviyesindedir. Mesleki kıdem yılına bakıldı ğında \%72,3'ünün 15 yıl aras1, \%11,7'sinin 6-10 y1l arası, \%10,6'sının 11-15 yıl aras1 ve \%5,3'ünün 16-20 yıl arası meslekte hizmet ettikleri görülmektedir. Aylık gelirleri ile ilgili olarak; \%38,9'unun 2500 TL veya daha düşük, \%24,5'inin 2501-3000TL aras1, \%21,3'ünün 3001-4000TL aras1, \%5,3'ünün 4001-5000TL aras1, \%10,1'inin 5001 TL ve üzeri olduğu görülmüştür.

Tablo 2. Katılımcıların Demografik Değişkenlere Göre Dağılımı

\begin{tabular}{|c|c|c|c|c|c|}
\hline Genel Bilgiler & Sayı & $\%$ & Genel Bilgiler & Sayt & $\%$ \\
\hline Cinsiyet & & & Medeni Durum & & \\
\hline Kadın & 138 & 71,9 & Bekar & 137 & 72,1 \\
\hline Erkek & 54 & 28,1 & Evli & 53 & 27,9 \\
\hline Toplam & 192 & 100 & Toplam & 190 & 100 \\
\hline Yaş & & & Öğrenim Durumu & & \\
\hline $20-30$ aras 1 & 137 & 71,4 & Ön Lisans & 5 & 2,6 \\
\hline $31-40$ aras 1 & 33 & 17,2 & Lisans & 169 & 88,9 \\
\hline $41-50$ aras 1 & 8 & 4,2 & Yüksek lisans & 12 & 6,3 \\
\hline 51 ve üzeri & 14 & 7,3 & Doktora & 4 & 2,1 \\
\hline Toplam & 192 & 100 & Toplam & 190 & 100 \\
\hline $\begin{array}{l}\text { Mesleki Kıdem } \\
\text { Yılı }\end{array}$ & & & Aylık Gelir & & \\
\hline $1-5$ y1l aras1 & 136 & 72,3 & & & \\
\hline $6-10$ y1l aras1 & 22 & 11,7 & 2500 TL veya düşük & 73 & 38,9 \\
\hline 11- 15 y1l arası & 20 & 10,6 & $2501-3000 \mathrm{TL}$ & 46 & 24,5 \\
\hline $16-20$ y1l aras 1 & 10 & 5,3 & 3001- 4000 TL aras1 & 40 & 21,3 \\
\hline \multirow[t]{2}{*}{21 yıl ve üzeri } & 0 & & $4001-5000 \mathrm{TL}$ & 10 & 5,3 \\
\hline & & & 5001 ve üzeri & 19 & 10,1 \\
\hline Toplam & 188 & 100 & Toplam & 188 & 100 \\
\hline
\end{tabular}

*Not: Tablolarda bazı sorulara yanıt vermeyen kişiler olduğundan toplam sayıların bir kısmı 192'nin altındadır. 


\section{DEĞİŞKENLER ARASI İLISŞKI BAZINDA BULGULAR}

\section{Korelasyon Analizi}

Korelasyon analizi iki veya daha fazla değişken arasında ilişki olup olmadığı, varsa ilişkinin yönü ve şiddetini hesaplamak için kullanılır. Çalışmada işyeri arkadaşlığ 1 ile mesleki tatmin arasında ve mesleki tatmin ile iş stresi değişkenleri arasında anlamlı ilişki olup olmadığını ve ilişkinin yönünü araştırmak için korelasyon testinden yararlanılmıştır. Tablo 1'de soru sayıları verilmiş olan değişkenler SPSS'te "ortalama hesaplama- compute mean" seçeneği kullanılarak tek değişken haline dönüştürülmüştür.

Korelasyon katsayısı -1 ile +1 arasında değişen değerler alır. Bu katsayı +1 değerine yakın ise iki değişken arasında pozitif yönlü bir ilişki, -1 değerine yakın ise iki değişken arasında negatif yönlü bir ilişki söz konusudur. Katsayı 0-0,3 arasında değerler alıyorsa ilişkinin zayıf, 0,3-0,7 arasında değerler alıyorsa ilişkinin orta, 0,7-1 arasında değerler alıyorsa ilişkinin kuvvetli olduğu yorumu yapılabilir (Gürbüz ve Şahin, 2016:264). Elde edilen verilere göre değişkenler arasında orta kuvvette korelasyon olduğu görülmektedir.

Tablo 3. Araştırma Değişkenlerine Yönelik Korelasyon Analizi

\begin{tabular}{|l|c|c|c|c|}
\hline \multicolumn{1}{|c|}{ Değişken } & $\mathbf{1}$ & $\mathbf{2}$ & $\mathbf{3}$ & $\mathbf{4}$ \\
\hline 1. İş arkadaşlığı - arkadaşlık firsatı & 1 & & & \\
\hline 2. İş arkadaşlığı - sıkı arkadaşık &, $668^{* *}$ & 1 & & \\
\hline 3. Mesleki tatmin &, $359^{* *}$ &, $286^{* *}$ & 1 & \\
\hline 4. İş stresi &,$- 476^{* *}$ &,$- 487^{* *}$ &,$- 330^{* *}$ & 1 \\
\hline
\end{tabular}

Not: ${ }^{* *} \mathrm{p} \leq 0.01$

Araştırma değişkenlerinden, iş arkadaşlığının iki alt boyutu olan arkadaşlık firsatı $\left(, 359^{* *}\right)$ ve sıkı arkadaşlık $\left(, 286^{* *}\right)$ ile mesleki tatmin arasında pozitif yönlü, mesleki tatmin ile iş stresi $\left(-, 330^{* *}\right)$ arasında negatif yönlü anlamlı ilişki olduğu bulgusuna ulaşılmıştır. Bu bulgular araştırma hipotezlerini doğrular yöndedir. 


\section{Regresyon Analizi}

Tablo 4. İşyeri arkadaşlığının (arkadaşlık firsatı ve sıkı arkadaşlık) mesleki tatmin üzerindeki etkisine yönelik regresyon analizi

\begin{tabular}{cccc}
\hline Değişken & Beta & t & $\boldsymbol{p}$ \\
\hline Arkadaşlık fırsatı &, 302 & 3,322 &, 001 \\
\hline Sıkı arkadaşık &, 085 &, 940 &, 348 \\
\hline
\end{tabular}

Düzeltilmiş $\mathbf{R}^{2}$ : ,123 F: 14,308 p: ,000

"H1. İsyyeri arkadaşlığının arkadaşlık firsatı boyutu mesleki tatmini olumlu olarak etkiler" hipotezi test etmek için yapılmış olan basit doğrusal regresyon modeli anlamlı olup $(\mathrm{F}=14,308 ; \mathrm{p}<0.01)$, işyeri arkadaşlığı mesleki tatmindeki değişimin \%12,3'ünü açıklamaktadır. Elde edilen bulgulara göre iş yeri arkadaşlığının arkadaşlık firsatı boyutu arttıkça mesleki tatmin artmaktadır. $\mathrm{Bu}$ bulgular 1şığında araştırmanın birinci hipotezi (H1) desteklenmektedir.

"H2. İsyeri arkadaşlı̆̆ının sıkı arkadaşlık boyutu mesleki tatmini olumlu olarak etkiler" hipotezini test etmek için yapılmış olan basit doğrusal regresyon modelinden elde edilen bulgulara göre araştırmanın ikinci hipotezi (H2) desteklenmemektedir.

Tablo 5. Mesleki tatminin iş stresi üzerindeki etkisine yönelik regresyon analizi

\begin{tabular}{cccccc}
\hline Değişken & Düzeltilmiş $\boldsymbol{R}^{2}$ & $\boldsymbol{F}$ & Beta & t & $\boldsymbol{p}$ \\
\hline $\begin{array}{c}\text { Mesleki } \\
\text { tatmin }\end{array}$ &, 104 & 22,799 &,- 330 & $-4,775$ &, 000 \\
\hline
\end{tabular}

"H3. Mesleki tatmin, iş stresini olumsuz etkiler" hipotezini test etmek için yapılmış olan basit doğrusal regresyon modelinin anlamlı olduğu $(F=22,799$; $\mathrm{p}<0.01)$ ve mesleki tatminin iş stresindeki değişimin \%10,4'ünü açıkladığı görülmektedir. İlişkinin yönünün negatif $(-, 330)$ olduğu görülmektedir. Elde edilen bulgulara göre mesleki tatmin arttıkça iş stresi azalmaktadır. Bu bulgular ışığında araştırmanın ikinci hipotezi (H3) desteklenmektedir. 


\section{SONUÇ VE TARTIŞMA}

İnsanlar sosyal varlıklardır ve başka insanlarla iletişim kurma, birlikte hareket etme, birlikte bir şeyleri paylaşma gibi sosyal davranışlar gösterirler. $\mathrm{Bu}$ davranışlar içerisinde başka insanlarla arkadaş olma en özel olanlardan birisidir. Sosyal ortamda var olan arkadaşlıklara ilave olarak insanlar çalıştıkları işyerlerinde de kendilerine yakın hissettikleri ve güvendikleri insanlarla arkadaşlıklar oluşturur ve hatta buna birey olarak ihtiyaç duyarlar. $\mathrm{Bu}$ arkadaşlıklar çalışanların duygusal olarak birbirlerini desteklemelerini sağlar ve sonuçta daha iyi performans göstermelerine ya da karşılaştıkları güçlüklerle başa çıkmalarına yardımcı olur. Arkadaşlık ağının genişliği de bu duruma katkı sağlayabilmektedir.

İnsanlar yaptıkları işlerin karşılığında bir gelir elde etmekle birlikte yaptıkları işi sevmeleri, kendilerini işleriyle özdeşleştirmeleri sonucu bir tatmin duygusu yaşayabilmektedirler. Özellikle hizmet sektöründe faaliyet gösteren çalışanların sundukları profesyonel hizmet esnasında mesleki tatmin duygusu oluşabilmektedir. Toplumumuzda özellikle öğretmenlerin, öğrencilerini yetiştirdikten yıllar sonra başarılarını gördüklerinde mutlu oldukları ve onlarla gurur duydukları bilinen bir gerçektir. Bu durum, kişinin mesleği ile ilgili vermiş olduğu hizmetin neticesinde kişide oluşan mesleki tatmin durumu olarak ifade edilmektedir. Benzer durum profesyonel meslek (avukatlık, doktorluk vb.) icra eden diğer meslek mensupları için de geçerlidir. Malatya'da yapılan bu çalışmada, özel eğitim kurumlarında görev yapan kişiler yönü ile konu ele alınmıştır. İşyeri arkadaş̧ığı boyutlarından arkadaşlık firsatı $\left(, 359^{* *}\right)$ ve sıkı arkadaşlık $\left(, 286^{* *}\right)$ ile mesleki tatmin arasında pozitif yönlü ilişki olduğu, işyeri arkadaşlığının mesleki tatmindeki değişimin \%12,3'ünü açıkladığı bulgusuna ulaşılmıştır. Bu bulgular eşliğinde işyeri arkadaşlığının mesleki tatmini pozitif yönlü olarak etkilediği ve işyeri arkadaşlığının arkadaşlık firsatı seviyesi arttıkça mesleki tatminin artmasına katkı sağladığg ifade edilebilir.

Stres kişilerin karşı karşıya kaldıkları zorluklara gösterdikleri psikolojik ve fizyolojik tepki ile ilgilidir. Çalışanları rahatsız edecek boyutlara ulaşmamak kaydı ile bir miktar stresin faydalı olduğu bilinmektedir. Fakat stres düzeyi çalışanları rahatsız edecek boyutlara ulaşırsa çalışanlarda psikolojik ve fizyolojik tepkiler oluşmasına sebep olmakta bu durum da çalışan performansına olumsuz olarak yansımaktadır. Dolayısıyla hem çalışan hem de işletme işten ayrılmaya kadar varabilen kayıplarla karşı karşıya kalınabilmektedir. İşletme içerisinde çalışanların yaşadığı mesleki tatminin iş stresine etki edeceği hipotezi ile yapılan araştırmada mesleki tatmin ile iş stresi $\left(-, 330^{* *}\right)$ arasında negatif yönlü anlamlı ilişki olduğu ve mesleki tatminin iş stresindeki değişimin \%10,4'ünü açıkladığı bulgusu elde edilmiştir. Mesleki tatmin düzeyi arttıkça iş stresinin azaldığ bulgulara göre ifade edilebilir. Li vd., (2014) ve Meyer vd. (2015)'nin yaptıkları 
çalışmada, yüksek düzeyde strese maruz kalanların mesleki tatminlerinin düştüğü sonucuna ulaştıkları çalışma ile benzer sonuca ulaşılmıştır. Bu çalışmalara tersinden bakışla mesleki tatminleri artanların stres düzeyleri düşmektedir.

Araştırmanın il olarak sadece Malatya'da uygulanmış olması ve özel eğitim kurumları ile kısıtlanmış olması araştırmanın sınırlılıklarındandır. Hizmet sektöründeki diğer mesleklerde de çalışmanın yenilenmesinin faydalı olacağı düşünülmektedir. İl ve mesleki çeşitliliğge gidilerek ayrıca daha büyük bir evrenden seçilen örneklem sayısı ile yapılacak olan gelecekteki çalışmaların bu sınırlılıkları azaltacağı öngörülmektedir.

Sonuç olarak, bu araştırma bulgularına göre, hizmet sektöründe görev yapan çalışanların mesleki tatminlerinin artırılması için işyerinde arkadaşlık iliş̧kilerinin güçlendirileceği çalışma ortamının hazırlanması ve hatta bireyler arasındaki formel ilişkilerin yanısıra informel ilişkilerin de yönetilmesi önerilmektedir. Mesleki tatminin artması, çalışanın iş stresini azalttığı için, kontrol edilemeyen stresin oluşturduğu negatif sonuçların minimize edilmesi açısından da mesleki tatmini artırıcı çabalara girişilmesi önerilmektedir.

\section{KAYNAKÇA}

Aktaş, Aliye Mavili (2001), "Bir kamu kuruluşunun üst düzey yöneticilerinin iş stresi ve kişilik özellikleri”, Ankara Üniversitesi SBF Dergisi, Vol:56, No:04, ss. 25-42.

Alkema, Karen; Linton, Jeremy. M. ve Davies, Randall (2008), “A study of the relationship between self-care, compassion satisfaction, compassion fatigue, and burnout among hospice professionals”, Journal of Social Work in End-of-Life \& Palliative Care, Vol:4, No:2, ss. 101-119.

Alparslan, Ali Murat; Çiçek, Hüseyin ve Soydemir, Salih (2015), "Birey-örgüt uyumunu güçlendiren öncül: işyeri arkadaşlı̆̆ı”, Akdeniz Üniversitesi İktisadi ve İdari Bilimler Fakültesi Dergisi, Vol:15, No:32, ss. 175-194.

Berman, Evan M.; West, Jonathan P. ve Richter, Maurice N. (2002), “Workplace relations: Friendship patterns and consequences (according to managers)”, Public Administration Review, Vol:62, No:2, ss. 217-230.

Bozgeyikli, Hasan (2016), “Özel Eğitim Öğretmenlerinin Çalışma Yaşamı Kalitelerinin Demografik Özellikler Açısından İncelenmesi”, Uluslararası Güncel Eğitim Araştırmaları Dergisi, Vol:2, No:1, ss. 94-110. 
Chang, Huo-Tsan; Chou, Yu-Jia; Liou, Jia-Wen ve Tu, Yi-Ting (2016), “The effects of perfectionism on innovative behavior and job burnout: Team workplace friendship as a moderator", Personality and Individual Differences, Vol: 96, ss. 260-265.

Conrad, David ve Kellar-Guenther, Yvonne (2006), "Compassion fatigue, burnout, and compassion satisfaction among Colorado child protection workers", Child abuse \& neglect, Vol: 30, No:10, ss. 10711080.

Craig, Carlton D. ve Sprang, Ginny (2010), “Compassion satisfaction, compassion fatigue, and burnout in a national sample of trauma treatment therapists”, Anxiety, Stress, \& Coping, Vol:23, No:3, ss. 319339.

Dobel, J. Patrick (2001), “Can Public Leaders Have Friends?”, Public integrity, Vol: 3, No: 2, ss.145-158.

Gupta, Nina ve Beehr, Terry A. (1979), “Job stress and employee behaviors", Organizational behavior and human performance, Vol: 23, No: 3, ss. 373-387.

Gürbüz, Sait ve Şahin, Faruk (2016), Sosyal Bilimlerde Araştırma Yöntemleri Felsefe-Yöntem-Analiz, Seçkin Yayıncılık, Ankara.

Harr, Cynthia (2013), "Promoting Workplace Health by Diminishing the Negative Impact of Compassion Fatigue and Increasing Compassion Satisfaction”, Social Work \& Christianity, Vol: 40, No: 1, ss. 71-88.

Hiçdurmaz, Duygu ve İnci, Figen Arı (2015), "Eşduyum yorgunluğu: tanımı, nedenleri ve önlenmesi”, Psikiyatride Güncel Yaklaşımlar, Vol:7, No:3, ss. 295-303.

Hooper, Crystal; Craig, Janet; Janvrin, David. R.; Wetsel, Margaret A. ve Reimels, Elanie (2010), “Compassion satisfaction, burnout, and compassion fatigue among emergency nurses compared with nurses in other selected inpatient specialties”, Journal of emergency nursing, Vol:36, No:5, ss. 420-427.

Karakaş, Ahmet Canan (2016), "Belediye çalışanlarında sabır tutumunun yaşam kalitesi üzerine etkisi (Sakarya İli Örneği)”, İnsan ve Toplum Bilimleri Araştırmaları Dergisi, Vol:5, No:8, ss. 2742-2757.

Lambert, Eric G.; Hogan, Nancy L.; Camp, Scott D. ve Ventura, Lois A. (2006), "The impact of work-family conflict on correctional staff: A 
preliminary study”, Criminology \& Criminal Justice, Vol:6, No:4, ss. 371-387.

Li, Angela; Early, Sean F.; Mahrer, Nicole E.; Klaristenfeld, Jessica L. ve Gold, Jeffrey I. (2014), “Group cohesion and organizational commitment: protective factors for nurse residents' job satisfaction, compassion fatigue, compassion satisfaction, and burnout”, Journal of Professional Nursing, Vol:30, No:1, ss. 89-99.

Mao, Hsiao-Yen (2006), “The relationship between organizational level and workplace friendship", The international journal of human Resource Management, Vol:17, No:10, ss. 1819-1833.

Methot, Jessica R.; Lepine, Jeffrey A.; Podsakoff, Nathan P. ve Christian, Jessica Siegel (2016), “Are workplace friendships a mixed blessing? Exploring tradeoffs of multiplex relationships and their associations with job performance", Personnel psychology, Vol:69, No:2, ss. 311-355.

Meyer, Rika M.L.; Li, Angela; Klaristenfeld, Jessica ve Gold, Jeffrey I. (2015), "Pediatric novice nurses: examining compassion fatigue as a mediator between stress exposure and compassion satisfaction, burnout, and job satisfaction”, Journal of pediatric nursing, Vol:30, No:1, ss. 174-183.

Morrison, Rachel L. (2009), "Are women tending and befriending in the workplace? Gender differences in the relationship between workplace friendships and organizational outcomes", Sex Roles, Vol:60, No:1, ss. 1-13.

Nielsen, Ivy. K.; Jex, Steve M. ve Adams, Gary A. (2000), "Development and validation of scores on a two-dimensional workplace friendship scale”, Educational and Psychological Measurement, Vol:60, No:4, ss. 628-643.

Parker, Donald F. ve DeCotiis, Thomas A. (1983), “Organizational determinants of job stress", Organizational behavior and human performance, Vol:32, ss. 160-177.

Riordan, Christina. M. ve Griffeth, Rodger W. (1995), "The opportunity for friendship in the workplace: An underexplored construct", Journal of business and psychology, Vol:10, No:2, ss. 141-154.

Severn, Micheal S.; Searchfield, Grant D. ve Huggard, Peter (2012), "Occupational stress amongst audiologists: Compassion satisfaction, 
compassion fatigue, and burnout”, International Journal of Audiology, Vol:51, No:1, ss. 3-9.

Sias, Patrici. M. ve Cahill, Daniel J. (1998), "From coworkers to friends: The development of peer friendships in the workplace", Western Journal of Communication (includes Communication Reports), Vol:62, No:3, ss. 273-299.

Sias, Patricia M.; Heath, Renee G.; Perry, Tara; Silva, Deborah ve Fix, Bryan (2004), "Narratives of workplace friendship deterioration", Journal of Social and Personal relationships, Vol:21, No:3, ss. 321-340.

Sias, Patricia M.; Pedersen, Hannah; Gallagher, Erin B. ve Kopaneva, Irina (2012), "Workplace friendship in the electronically connected organization”, Human Communication Research, Vol:38, No:3, ss. 253279.

Speegle, Micheal (2013), Safety, Health, and Environmental Concepts for the Process Industry, (2nd Edition), Delmar Cengage Learning, U.S.A NewYork.

Stamm, Beth Hudnall (2010), The Concise ProQOL Manual, 2nd Ed. Pocatello.

Şahinbaş, Furkan ve Erigüç, Gülsün (2019), "Pozitif Örgütsel Davranış Yaklaşımıyla İşyeri Arkadaşlığı ve İşe Adanma İlişkisi: Sağlık Çalışanları Üzerine Bir Araştırma”, Uluslararası Yönetim İktisat ve İşletme Dergisi, Vol:15, No:4, ss. 1201-1225.

Wagaman, M. Alex; Geiger, Jennifer M.; Shockley, Clara ve Segal, Elizabeth A. (2015), "The role of empathy in burnout, compassion satisfaction, and secondary traumatic stress among social workers", Social work, Vol:60, No:3, ss. 201-209.

Yeşil, Asl1; Ergün, Ümit; Amasyal, Cumhur; Er, Fatih; Olgun, Nesligül Nihal ve Aker, A. Tamer (2010), "Çalışanlar İçin Yaşam Kalitesi Ölçeği Türkçe Uyarlaması Geçerlik ve Güvenilirlik Çalışması”, Archives of Neuropsychiatry/Noropsikiatri Arsivi, Vol:47, No:2, ss. 111-117.

Yılmaz, Gülay ve Üstün, Besti (2018), "Hemşirelerde profesyonel yaşam kalitesi: Merhamet memnuniyeti ve merhamet yorgunluğu”, Psikiyatri Hemşireliği Dergisi, Vol:9, No:3, ss. 205-211. 